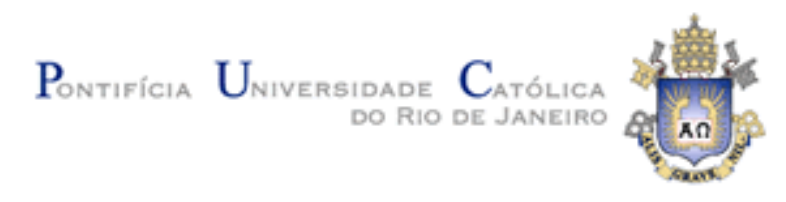

Victor Almeida Santos de Freitas

\title{
Reação da Política Fiscal e Sustentabilidade da Dívida Federal no Brasil, 1994-2008
}

Dissertação de Mestrado

Dissertação apresentada como requisito parcial para obtenção do título de Mestre pelo Programa de PósGraduação em Economia da PUC-Rio.

Orientadores: Afonso Sant'Anna Bevilaqua Rogério Furquim Werneck 


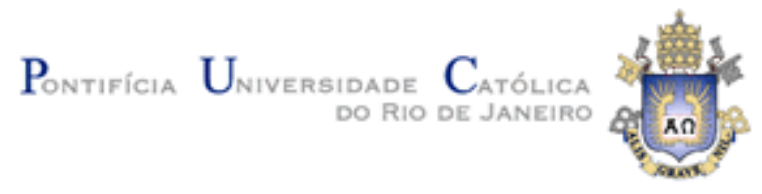

Victor Almeida Santos de Freitas

\title{
Reação da Política Fiscal e Sustentabilidade da Dívida Federal no Brasil, 1994-2008
}

Dissertação apresentada como requisito parcial para obtenção do título de Mestre pelo Programa de PósGraduação em Economia da PUC-Rio. Aprovada pela Comissão Examinadora abaixo assinada.

\author{
Prof. Afonso Sant'Anna Bevilaqua \\ Orientador \\ Departamento de Economia - PUC-Rio \\ Prof. Rogério Furquim Werneck \\ Co-Orientador \\ Departamento de Economia - PUC-Rio \\ Prof. Marcelo Cunha Medeiros \\ Departamento de Economia - PUC-Rio \\ Prof. Alexandre Schwartsman \\ Santander \\ Profa. Mônica Herz
}

Coordenadora Setorial do Centro de Ciências Sociais - PUC-Rio

Rio de Janeiro, 9 de abril de 2010 
Todos os direitos reservados. É proibida a reprodução total ou parcial do trabalho sem autorização da universidade, do autor e do orientador.

\section{Victor Almeida Santos de Freitas}

Graduou-se em Economia no Insper em 2007, cursando o Mestrado no departamento de economia da PUC-Rio entre 2008 e 2009.

Ficha Catalográfica

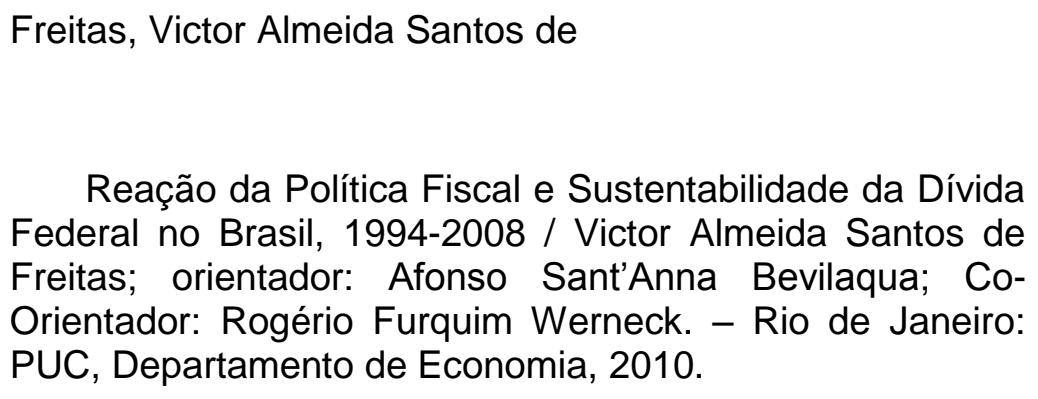

Reação da Política Fiscal e Sustentabilidade da Dívida Federal no Brasil, 1994-2008 / Victor Almeida Santos de Freitas; orientador: Afonso Sant'Anna Bevilaqua; CoOrientador: Rogério Furquim Werneck. - Rio de Janeiro: PUC, Departamento de Economia, 2010.

55 f. : il. (color.) ; $30 \mathrm{~cm}$

Dissertação (Mestrado em Economia) - Pontifícia Universidade Católica do Rio de Janeiro, Rio de Janeiro, 2010.

Incluí referências bibliográficas.

1. Economia - Teses. 2. Sustentabilidade da política fiscal. 3. Função de Reação Fiscal. 4. Restrição Orçamentária Intertemporal. 5. Política Fiscal. 6. Previsão em Séries Temporais. I. Bevilaqua, Afonso Sant'Anna. II. Werneck, Rogério Furquim. III. Pontifícia Universidade Católica do Rio de Janeiro. Departamento de Economia. IV. Título. 


\section{Agradecimentos}

Aos meus orientadores e professores Afonso Bevilaqua e Rogério Werneck pelo apoio, incentivo e lições tanto para a realização deste trabalho quanto para minha carreira como economista.

Aos membros da minha banca Marcelo Medeiros e Alexandre Schwartsman pelo tempo dedicado a leitura da minha dissertação e pelos conselhos que colaboraram para esse estudo.

Ao CNPq e à PUC-Rio, pelos auxílios concedidos, sem os quais este trabalho não poderia ter sido realizado.

Aos meus pais, irmã e namorada pela paciência durante esses dois anos.

Aos amigos pelo apoio nos momentos críticos. 


\section{Resumo}

Freitas, Victor Almeida Santos; Bevilaqua, Afonso Sant'Anna; Werneck, Rogério Furquim. Reação da Política Fiscal e Sustentabilidade da Dívida Federal no Brasil, 1994-2008. Rio de Janeiro, 2010. 55p. Dissertação de Mestrado - Departamento de Economia, Pontifícia Universidade Católica do Rio de Janeiro.

O período de 1994 a 2008 caracteriza um momento da história físcal brasileira importante. Durante esse período observou-se uma retomada do controle sobre o endividamento público, por meio de aumento expressivo do superávit primário. Nesta dissertação essa correção é analisada, qualitativamente e quantitativamente, mostrando que a condução austera da política fiscal foi capaz de estabilizar a trajetória do endividamento. Salienta-se a importância de uma posição primária que dependa dos movimentos da dívida, garantindo seu controle em um patamar estável. Foram feitos testes tradicionais da literatura, em que se avaliam diretamente os movimentos conjuntos das variáveis, e, adicionalmente, testa-se o poder preditivo do endividamento sobre o superávit primário. Apesar de encontrar evidências de que a correção na posição primária foi suficiente para induzir o controle do movimento da dívida, a análise qualitativa aponta para uma fonte de instabilidade, o crescimento constante das despesas primárias.

\section{Palavras-chave}

Sustentabilidade da política fiscal; Função de Reação Fiscal; Restrição Orçamentária Intertemporal; Política Fiscal; Previsão em Séries Temporais. 


\section{Abstract}

Freitas, Victor Almeida Santos; Bevilaqua, Afonso Sant'Anna (Advisor); Werneck, Rogério Furquim (Advisor). Fiscal Policy Response and Public Debt Sustainability in Brazil, 1994-2008. Rio de Janeiro, 2010. 55p. MSc. Dissertation - Departamento de Economia, Pontifícia Universidade Católica do Rio de Janeiro.

The years between 1994 and 2008 were a very important period in Brazil's fiscal history. The government regained control over its public deficit during those 14 years by increasing its primary surplus to as much as $3 \%$ of gross domestic product. This dissertation analyses these changes through qualitative and quantitative methods, exposing the strict fiscal policies that led to control of public debt. It also places emphasis on the significance of an active fiscal policy on public debt levels and the size of the primary surplus. Traditional tests were utilized to evaluate fiscal policy sustainability and, in addition, tests how the primary surplus is impacted, and predicated, by public debt levels. While there is enough evidence showing how primary balance adjustments were sufficient for stabilizing the debt in question, qualitative analysis points out a new source of instability: the continuous growth of primary expenses.

\section{Keywords}

Fiscal Sustainability; Fiscal Policy Reaction Function; Intertemporal Budget Constraint; Fiscal Policy; Time Series Forecasting. 


\section{Sumário}

1 Introdução 10

2 Política Fiscal no Brasil, 1996 - 2008

3 Sustentabilidade e Função de Reação 27

4 Análise Empírica 38

4.1. Estratégia empírica 39

4.2. Teste de Johansen 39

4.3. Estacionariedade 41

4.4. Teste de Previsibilidade $\quad 45$

5 Comentários Finais $\quad 49$

6 Referências Bibliográficas $\quad 51$ 


\section{Lista de figuras}

Figura 2-1: Dívida líquida x Resultado Primário - Governo Central 13

Figura 2-2: Câmbio Real x Dívida Líquida Federal 17

Figura 2-3: Receitas Primárias e Despesas primárias - 1994 / $2008 \quad 24$

Figura 4-1: Receita e despesa primárias 43

Figura 4-2: Resultado Primário e Nominal 43

Figura 4-3: Dívida Líquida e Despesas inclusive juros 43

Figura 4-4: Dívida Líquida Descontada (\%PIB) 44

Figura 4-5: Taxa de desconto 45

Figura 4-6: Estimativas do processo de reamostragem 48 


\section{Lista de tabelas}

Tabela 2-1: Resultado Primário do Governo Central - 1995/1998 12

Tabela 2-2: Resultado Fiscal do Governo Central - 1994 / 1998

Tabela 2-3: Resultado Primário do Governo Central - 1999 / $2002 \quad 19$

Tabela 2-4: Resultado Fiscal do Governo Central - 1999 / 2002

Tabela 2-5: Resultado Primário do Governo Central - 2003 / $2006 \quad 20$

Tabela 2-6: Resultado Primário do Governo Central - 2007 / $2008 \quad 20$

Tabela 2-7: Resultado Fiscal do Governo Central - 2003 / 2008

Tabela 2-8: Dinâmica da Dívida (2001/2008) 25

Tabela 2-9: Despesas Primárias do Governo Central 26

Tabela 2-10: Outras Despesas 26

Tabela 3-1: Resumo da Literatura Internacional 36

Tabela 3-2: Resumo da Literatura Nacional 37

Tabela 4-1: Teste de cointegração: superávit primário e dívida líquida 40

Tabela 4-2: Testes de estacionariedade 42

Tabela 4-3: Ordem Ótima do Processo Auto-Regressivo 46

Tabela 4-4: Resultado de significância do teste de Diebold-Mariano 48 